\title{
AVALIAÇÃO DE EFICIÊNCIA DE TERMINAIS DE CONTÊINERES NO BRASIL ATRAVÉS DA ANÁLISE ENVOLTÓRIA DE DADOS (DEA) ${ }^{1}$
}

\author{
EVALUATION OF EFFICIENCY OF CONTAINER TERMINALS IN BRAZIL \\ THROUGH ANALYSIS ENVELOPE DATA (DEA)
}

\author{
Marcelo Alvaro da Silva Macedo ${ }^{2}$ \\ João Victor da Paschoa Manhães ${ }^{3}$
}

RESUMO: Este trabalho busca analisar a eficiência de operação de 10 terminais de contêineres no Brasil. Isso é feito pela aplicação da metodologia de Análise Envoltória de Dados (DEA) às informações referentes a movimentação, produtividade, área disponível, tamanhos de calado e de berço. Foram analisadas a eficiência técnica global (obtida pela fronteira DEA-CRS), a eficiência técnica pura (obtida pela fronteira DEA-VRS) e a eficiência de escala (obtida pela razão CRS/VRS). Os resultados mostram que apenas os terminais Santos-Brasil, TVV e Tecon Salvador é que são totalmente eficientes.

PALAVRAS-CHAVE: Terminais de Contêineres; Desempenho; Eficiência; DEA.

ABSTRACT: This study attempts to analyze the operation efficiency of 10 containers terminals in Brazil. This is done by applying the Data Envelopment Analysis (DEA) methodology for information about container handling, productivity, total area, sizes of depth and berths. We analyzed the global efficiency(obtained by the DEA-CRS border), the technical efficiency (obtained by the DEA-CRS border) and efficiency of scale (obtained by the ratio $C R S / V R S)$. The results show that only the terminals Santos Brasil, TVV and Tecon Salvador are totally efficient.

KEY WORDS: Containers Terminals; Performance; efficiency; DEA.

\footnotetext{
${ }^{1}$ Artigo Recebido em 03.12.2008. Revisado por pares em 05.06.2009. Recomendado em 02.12.2009 por Leomar dos Santos Editor. Publicado em 06.03.2010.

Organização Responsável pelo periódico: Universidade regional de Blumenau - FURB - www.furb.br/rn

${ }^{2}$ Universidade Federal do Rio de Janeiro - UFRJ - malvaro.facc.ufrj@gmail.com

${ }^{3}$ Universidade Federal Rural Rio de Janeiro - UFRuralRJ - jvmanhaes@yahoo.com.br
} 


\section{INTRODUÇÃO}

Os portos são o principal meio de entrada e saída de mercadorias de um país. De acordo com Rios (2005), os portos são responsáveis pela movimentação de $90 \%$ da carga internacional, sendo que, dessa, $80 \%$ é feita através de contêineres. Segundo Rios e Maçada (2006), aproximadamente $95 \%$ do comércio exterior brasileiro é realizado por via marítima, principalmente por contêineres.

O transporte de carga em contêineres é uma tendência mundial, abarcando não somente países desenvolvidos, como países em desenvolvimento. A utilização de contêineres oferece uma maior eficiência no transbordo da carga e, em conseqüência, essa redução de tempo na troca de modais reduz os custos de transportes, aumentando a margem de lucro das empresas (HIJJAR e ALEXIM, 2006).

Para Cullinane et al. (2005), a globalização da economia mundial conduziu o transporte a um papel cada vez mais importante. Em particular, o transporte em contêiner desempenha um papel fundamental neste processo, em grande parte devido às numerosas vantagens técnicas e econômicas que possui sobre os métodos tradicionais de transporte. Ainda para os autores, a conteinerização é crucial na interface entre as vias marítimas e terrestres.

Segundo Bandeira (2005), o uso de contêineres facilitou muito as operações de manipulação em portos e em outros pontos de transferência, aumentando a eficiência e a velocidade do transporte, permitindo que múltiplas unidades de carga fossem manipuladas simultaneamente.

De acordo com a ABRATEC (Associação Brasileira dos Terminais de Contêineres de Uso Público), a operação de contêineres nos terminais brasileiros tem registrado altos índices de crescimento. A quantidade movimentada passou de 1.198 .484 unidades em 1996 para 4.083.150 em 2006, tendo registrado, portanto, um acréscimo de $341 \%$ no período. Para a associação, esse aumento deveu-se à eficiência operacional dos terminais especializados, que já realizaram investimentos de US\$ 1 bilhão na construção de obras físicas, aquisição de modernos equipamentos e especialização de mão-de-obra. Em 2007 foram movimentados 4.399.073 contêineres nos portos brasileiros, e a previsão da movimentação de contêineres para o ano de 2010 é de 7.020 .669 unidades.

A globalização, o crescimento do comércio internacional e a importância do modal marítimo fazem com que as empresas do setor e os governos busquem novas ferramentas e técnicas para avaliar o desempenho de suas organizações em comparação com as demais do setor.

É nessa perspectiva que este trabalho busca se inserir. Sendo assim, o objetivo deste estudo é analisar as eficiências de operação técnica global, técnica pura e de escala de 10 terminais de contêineres no Brasil, pela aplicação da metodologia de Análise Envoltória de Dados (DEA) às informações do ano de 2007 referentes a movimentação, produtividade, área disponível, tamanho de calado e de berço.

Para tanto, utiliza-se uma amostra por acessibilidade de 10 terminais associados da Associação Brasileira de Terminais de Contêineres de Uso Público (ABRATEC). Desses terminais, são obtidos dados secundários no site da ABRATEC referentes à Movimentação de 
Contêineres e Produtividade na Movimentação de Contêineres (como outputs do processo), e Área Total das Instalações, Extensão Média dos Berços e Calado dos Berços de Atracação (como inputs). Com essas variáveis, foram montadas duas modelagens de análise: a primeira referente à produção (utilizando todos os inputs e apenas a Movimentação de Contêineres como output); a segunda referente à produtividade (também utilizando todos os inputs e apenas a Produtividade na Movimentação de Contêineres como output).

Através da aplicação da DEA, as modelagens aplicadas buscam calcular a eficiência organizacional multidimensional na obtenção da maior Movimentação de Contêineres ou Produtividade na Movimentação de Contêineres possível com o menor uso possível de Área Total das Instalações, Extensão Média dos Berços e Calado dos Berços de Atracação, considerando de maneira integrada todos os vetores de desempenho apresentados. Cabe salientar que foram analisadas a eficiência técnica global (obtida com a fronteira DEA-CRS), a eficiência técnica pura (obtida pela fronteira DEA-VRS) e a eficiência de escala (obtida pela razão CRS/VRS).

Por fim, destaca-se que, além dessa parte contendo a introdução do trabalho, o artigo se divide em uma segunda parte sobre desempenho e DEA, uma terceira sobre aplicações de DEA em portos e terminais de contêineres, uma quarta parte sobre a metodologia, uma quinta onde apresenta-se e analisa-se os resultados, e por ultimo a conclusão e as considerações finais, seguidas das referências bibliográficas.

\subsection{Desempenho e Análise Envoltória de Dados (DEA)}

A globalização e a abertura dos mercados fizeram com que as organizações sofressem mudanças para se adaptarem ao novo quadro mundial. Nesse quadro, em que a competitividade é um fator determinante, os sistemas de medição de desempenho se tornaram indispensáveis.

A mensuração de desempenho é definida por Neely (1998) como sendo o processo de quantificar a eficiência e a efetividade de ações passadas, através da aquisição, coleta, classificação, análise, interpretação e disseminação dos dados apropriados. Ao final dessa trajetória, os sistemas de medição fornecem o grau de evolução, estagnação ou involução dos processos e atividades das empresas sob análise, gerando informações importantes e a tempo de que as ações preventivas e/ou corretivas sejam tomadas. Como o progresso da empresa é monitorado através desses sistemas, seus eventuais erros podem ser corrigidos, aumentando as possibilidades de que essas conquistem suas metas e objetivos.

De acordo com Macedo (2004), os processos de mensuração de desempenho se desenvolvem a partir da seleção de indicadores críticos de desempenho específicos para cada empresa. Entretanto, a maior dificuldade dos gestores está na escolha desses indicadores. $\mathrm{O}$ principal meio de definir esses indicadores seria, primeiramente, definir onde a organização se encontra e aonde quer chegar, para posteriormente definir os mecanismos que farão com que isso seja possível. Tais processos são permanentes e repetitivos, sendo a freqüência de suas medições dependente da atividade a ser medida.

Para Slack et al. (2002), toda organização precisa, de alguma forma, de medidas de desempenho como um pré-requisito para melhoramento. No entanto, as práticas de medição 
de desempenho variam entre as empresas. Cabe ressaltar, porém, que depois da mensuração de desempenho, usando, normalmente, um conjunto de medidas parciais, a organização precisa fazer um julgamento sobre sua performance. Esse julgamento, segundo os autores, envolve a comparação do nível de desempenho atingido com algum tipo de padrão. Esses padrões podem ser:

- Padrões Históricos: consistem na comparação do desempenho atual com desempenhos anteriores, construindo assim uma tendência do comportamento de desempenho ao longo do tempo;

- Padrões de Desempenho Alvos: são aqueles estabelecidos arbitrariamente para refletir algum nível de desempenho que é visto como adequado;

- Padrões de Desempenho da Concorrência: utilizam a comparação do desempenho atingido com aquele que está sendo conseguido por um ou mais competidores;

- Padrões de Desempenho Absolutos: são aqueles tomados em seus limites (ex.: estoque zero, zero defeito, etc.).

Quando as empresas utilizam o mercado como parâmetro de comparação, segundo padrões de desempenho da concorrência, é necessário que se use uma abordagem denominada benchmarking. Essa abordagem consiste na performance relativa das empresas em função de um conjunto de competidores previamente selecionados (SLACK et al. 2002).

Camp (1989) define benchmarking como sendo um processo sistemático para a identificação da melhor prática e para a modificação do conhecimento existente, de modo a alcançar um desempenho superior. Para Novaes (2001), benchmarking é considerado um processo contínuo e sistemático de empresas e serviços, através da sua comparação com unidades consideradas eficientes, levando ao estabelecimento de ações gerenciais efetivas, com o objetivo de aprimorar os resultados (redução de custos, aumento de produção, etc.); Além de ser um dos modernos instrumentos de gerência, que possibilita a melhoria do desempenho técnico-econômico das empresas de forma comparativa ou relativa.

Os sistemas de mensuração de desempenho são essenciais para que as organizações possam competir no mercado global. Porém, as avaliações feitas em caráter relativo (ou seja, mensurando a eficiência da organização em relação, por exemplo, ao seu ambiente competitivo) são geradoras de resultados potencialmente consistentes. Isso ocorre à medida de que informam o posicionamento da empresa perante a referência e as demais empresas.

Não existe possibilidade de reduzir a complexidade do desempenho de um negócio a um único indicador, havendo necessidade real de aplicar diversos indicadores para atingir os mais variados aspectos nos quais a estratégia de negócio se realiza. (SLACK et al.., 2002) Assim, um programa de avaliação de desempenho eficiente deve incluir todos esses elementos considerados críticos de sucesso. Isto quer dizer que todos os elementos relevantes às empresas, de maneira individual, precisam ser, de alguma forma, mensurados para permitir análises comparativas.

São inúmeras as variáveis do mundo empresarial passíveis de mensuração. No entanto, não existem, ainda, modelos de avaliação de performance únicos para todas essas variáveis. A solução encontrada pelos gestores é a utilização de uma série de metodologias de avaliação capazes de tratar os diferentes elementos da organização. Essas técnicas produzem resultados isolados, uma vez que não consideraram a multiplicidade de fatores numa única análise. 
Nesse sentido, a Análise Envoltória de Dados (DEA) apresenta-se como uma medida de desempenho capaz de comparar a eficiência de várias unidades operacionais similares mediante a consideração explícita do uso de suas múltiplas entradas para a produção de múltiplas saídas. Dessa forma, essa metodologia faz com que a decisão fique orientada por um único indicador construído a partir de várias abordagens de desempenho diferentes. Portanto, como congrega diversas perspectivas, a técnica promove uma melhor percepção da performance organizacional.

Segundo Macedo (2004), a metodologia DEA, que teve origem no trabalho de Farrell (1957), caracteriza-se como uma técnica não paramétrica que permite lidar com várias saídas (outputs) e entradas (inputs), com o objetivo de analisar, comparativamente, unidades independentes no que se refere ao seu desempenho, ou seja, à eficiência de cada unidade.

De acordo com Lins e Meza (2000), a DEA se propõe a analisar a relação recursos/produção, ou ainda, entradas/saídas, envolvida na avaliação do desempenho de unidades organizacionais, indicando os fatores que interferem positiva ou negativamente sobre a eficiência dessas. Sendo assim, um dos maiores benefícios do uso da DEA é o conjunto de unidades de referência que pode ser usado como benchmarking na melhoria do desempenho das unidades menos eficientes. Esses benchmarks indicam o que precisa ser modificado nos inputs e outputs e como melhorá-los para transformar unidades ineficientes em eficientes.

A Análise Envoltória de Dados (DEA), segundo Coelli et al. (1998), representa uma das mais adequadas ferramentas para avaliar a eficiência, em comparação com ferramentas convencionais. Os resultados de DEA são mais detalhados do que os obtidos em outras abordagens, servindo melhor ao embasamento de recomendações de natureza gerencial. Sendo assim, os autores destacam as seguintes características da ferramenta em questão:

- Não requer a priori uma função de produção explícita;

- Examina a possibilidade de diferentes, mas igualmente eficientes combinações de inputs e outputs;

- Localiza a fronteira eficiente dentro de um grupo de unidades analisadas e

- Determina, para cada unidade ineficiente, subgrupos de unidades eficientes, os quais formam seu conjunto de referência.

São várias as formulações dos modelos de DEA encontradas na literatura, conforme dizem Charnes et al. (1994), entretanto dois modelos básicos DEA são geralmente usados nas aplicações. O primeiro modelo chamado de CCR (CHARNES, COOPER e RHODES, 1978), também conhecido como CRS (Constant Returns to Scale), avalia a eficiência total, identifica as DMUs eficientes e ineficientes e determina a que distância da fronteira de eficiência estão as unidades ineficientes. O segundo, chamado de modelo BCC (BANKER, CHARNES e COOPER, 1984), também conhecido como VRS (Variable Returns to Scale), utiliza uma formulação que permite a projeção de cada unidade ineficiente sobre a superfície de fronteira (envoltória) determinada pelas unidades eficientes de tamanho compatível.

No caso das formulações, além das da escolha entre CRS e VRS, existe a necessidade de fixação da ótica de análise (orientação input ou orientação output). Macedo (2006) diz que a abordagem DEA baseada nas entradas (inputs) busca maximizar as quantidades de produtos, isto é, maximizar uma combinação linear das quantidades dos vários produtos da empresa. Já 
para uma abordagem baseada nas saídas (outputs), busca-se minimizar as quantidades de insumos, isto é, minimizar uma combinação linear das quantidades dos vários insumos da empresa.

De acordo com Macedo (2006), dentre as propriedades que levaram essa técnica a ser adotada como o método de análise de vários estudos, podem-se destacar as seguintes:

- Diferença em relação aos métodos que necessitam que todos os inputs e outputs sejam transformados em uma única unidade de medida;

- Constituição de uma alternativa aos métodos tradicionais de análise de tendência central e custo-benefício;

- Possibilidade de consideração dos outliers (valores que estão bem afastados da mediana dos dados) não apenas como desvios em relação ao comportamento médio ou mediano dos dados, mas como pontos que podem ser possíveis benchmarks para serem estudados pelas demais unidades (de modo a aprender com os melhores daquele segmento);

- Possibilidade de identificação das dimensões da ineficiência relativa de cada uma das unidades comparadas, bem como do índice de eficiência de cada uma;

- Constituição baseada em informações individuais de cada unidade, também chamada de DMU (Decision Making Unit), sendo possível utilizar múltiplos outputs e múltiplos inputs, com variáveis em unidades completamente diferentes;

- Possibilidade de identificação de qualidades comuns entre os mais/menos eficientes.

\section{APLICAÇÃO DE DEA EM PORTOS E/OU TERMINAIS DE CONTÊINERES}

De acordo com Cullinane et al. (2005) entender o processo de produção é um prérequisito determinante para a melhoria da eficiência de produção.

Segundo Rios e Maçada (2002), as operações portuárias podem ser divididas em: i) receber (que consiste no transporte de contêineres de exportação trazidos pelos caminhões dos portões de entrada para o pátio de contêiner); ii) entregar (que é o inverso da tarefa anterior, só que com os contêineres de importação); iii) carregar (que é transportar os contêineres de exportação do pátio de contêiner para o navio); e iv) descarregar (que consiste em retirar os contêineres de importação do navio e transportar para o pátio de contêiner).

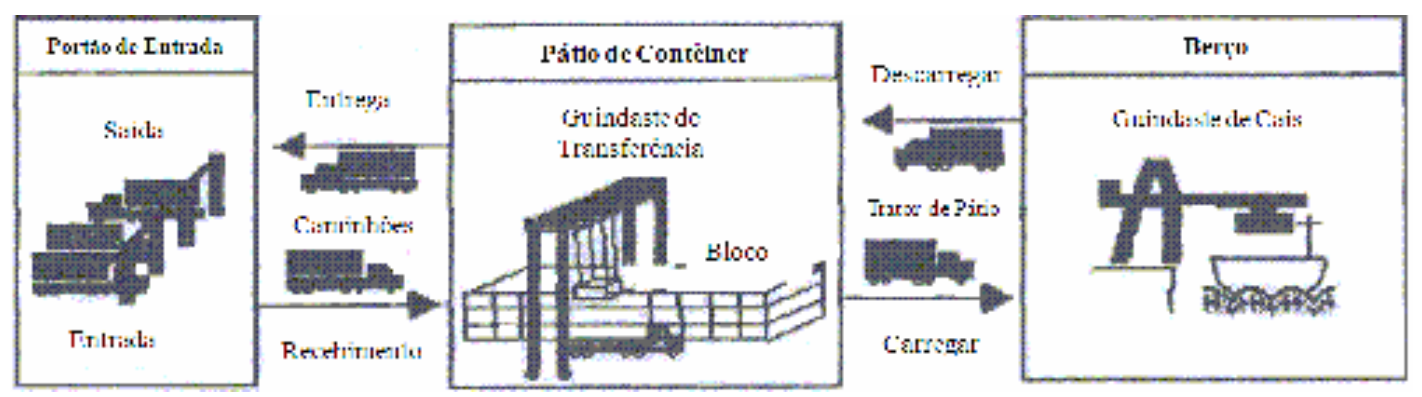

Figura 01 - Operação de um Terminal de Contêineres

Fonte: Rios e Maçada (2002) 
Já para Cullinane et al. (2005) as operações de um terminal de contêiner geralmente podem ser divididas em operações de transferência de cais ao longo do berço, sistemas de armazenamento no cais dos terminais de contêineres, operações de gate, e assim por diante.

As medidas dos contêineres são normalmente expressas em TEUs (Twenty-foot Equivalent Units). Um TEU equivale a oito pés de largura, oito pés de altura e 20 pés de comprimento. Um contêiner de 40 pés equivale a dois TEUs. Além do tamanho, os contêineres também podem diferenciar-se para atender requisitos da carga transportada. A conteinerização de alimentos perecíveis (como carne, por exemplo) exige uma tecnologia de refrigeração acoplada ao contêiner, tornando-o um contêiner refrigerado.

Rios (2005) afirmou que os primeiros autores a aplicarem a DEA em portos foram Roll e Hayuth (1993). Esses autores utilizaram dados hipotéticos de 20 portos para mostrar como as eficiências poderiam ser mensuradas. Segundo Rios (2005), foram utilizados quatros outputs: nível de serviço (diferença entre tempo de movimentação e o tempo total em que o navio fica no porto), movimentação de carga, satisfação do usuário e número de atracações; e três inputs: total de capital investido, número de funcionários e tipo de carga.

Barros e Athnassiou (2004) analisaram a eficiência de seis terminais de contêineres europeus, sendo quatro portugueses e dois gregos. Os autores utilizaram dois indicadores para medir os inputs, o trabalho (mensurado pelo número de trabalhadores) e capital (medido pelo valor dos ativos). Como outputs foram utilizados os indicadores: número de navios, circulação de mercadorias, quantidade de carga movimentada e quantidade de contêineres movimentados (TEUs / ANO). As variáveis são referentes aos anos de 1998 a 2000 . O método de análise foi DEA nos modelos CCR e BCC, ambos orientados por inputs. As conclusões principais foram de que ao se utilizar a técnica DEA no modelo CCR, todos os portos foram eficientes com exceção dos portos de Tessaloniki e Setubal e que ao se utilizar a técnica DEA no modelo BCC, apenas o porto de Tessaloniki foi ineficiente dentre do grupo comparativo. $\mathrm{O}$ trabalho concluiu que a fonte dominante de eficiência era a escala. $\mathrm{O}$ que justifica a ineficiência do porto de Tessaloniki, localizado na região dos Balcãs, que operou no período de análise com baixo volume de movimentação de contêineres e mercadorias.

Cullinane et al. (2004) utilizaram a técnica DEA Windows para avaliar o desempenho dos 30 maiores portos do mundo no ano de 2001. O período de análise foi de 1992 a 1999, e utilizou-se como inputs o comprimento de cais, a área do terminal, número de guindastes de berço, número de guindastes de pátio e número de Straddle Carrier, e como output a movimentação de contêineres em TEUs movimentados em cada ano. O trabalho concluiu que a eficiência dos portos e/ou terminais de contêineres podem variar ao longo do tempo e que os atuais métodos de programação para estimar a eficiência são insuficientes ao se trabalhar ao longo do tempo.

Rios e Maçada (2006), por sua vez, avaliaram o desempenho de 23 terminais de contêineres do Mercosul, sendo 15 terminais brasileiros, 6 argentinos e 2 uruguaios. Os autores utilizaram como variáveis de inputs o número de guindastes, número de berços, área do terminal, número de funcionários e o número de equipamentos de pátio, enquanto as variáveis de outputs foram a quantidade de TEUs movimentadas e a movimentação média de contêineres por hora. A técnica DEA no modelo BCC foi utilizada para medir a eficiência relativa entre os terminais, e a Regressão Tobit verificou as variáveis que mais influenciavam 
a eficiência. Ao se utilizar a Regressão Tobit, constatou-se que a variável "número de equipamentos de pátio" não apresentava nenhuma significância estatística. Esse resultado surpreendeu os pesquisadores, pois essa variável foi apontada pelos executivos dos terminais de contêineres como sendo de extrema importância na eficiência das operações portuárias.

Cullinane et al. (2005) utilizaram como amostra 57 entidades, sendo portos e/ou terminais de contêineres. Nesse trabalho, as variáveis de entrada foram o comprimento do cais, a área do terminal, o número de guindastes de berço, o número de guindastes de pátio e o número de Straddle Carrier. Como saída, foi considerada a movimentação de contêineres em TEUs. Para essa amostra, os autores utilizaram duas técnicas não-paramétricas a DEA, nos modelos BCC e CCR e a FDH (Free Disposal Hull) para mensurar a eficiência das DMUs. Ambas as técnicas são utilizadas para medir a eficiência de DMUs com várias entradas e saídas. As principais conclusões do trabalho deles foram que as metodologias de programação matemática disponíveis conduzem a diferentes resultados e que a disponibilidade de painel de dados (em detrimento do cruzamento de dados seccionais) melhoraria significativamente a validade das estimativas de eficiência referentes a todas as técnicas de programação matemática aplicadas. Um dos resultados que mais surpreendeu os autores foi, ainda, o fato de alguns dos principais portos (como o MTL, em Hong Kong) atualmente sofrerem de ineficiência. Uma das possíveis explicações seria um investimento recente em infraestrutura de apoio à produção futura, ainda sem impacto sobre o volume de movimentação, justificando a necessidade de se trabalhar com dados em painel.

Wang e Cullinane (2006) também aplicaram DEA, nos modelos BCC e CCR, para avaliar a eficiência relativa dos terminais de contêineres europeus que tiveram volume de movimentação superior a 10.000 TEUs no ano de 2003, perfazendo um total de 104 terminais. Para análise, os autores utilizaram três variáveis de entrada (inputs) o comprimento de cais, a área do terminal e os custos anuais com os equipamentos. A única variável de saída considerada foi a movimentação de contêineres (TEUs). As principais constatações desse estudo foram a grande ineficiência que prevalece na maioria dos terminais, tanto na aplicação do modelo BCC quanto do modelo CCR, e que a produção em grande escala tende a estar associada a uma maior eficiência.

Fontes e Mello (2006), mais próximos ao nosso ambiente, aplicaram DEA no modelo BCC com orientação de output para avaliar a eficiência de 31 portos brasileiros. Na análise foram considerados os dados referentes aos anos de 2002, 2003 e 2004, divulgados pela ANTAQ (Agência Nacional de Transportes Aquaviários). Como variáveis foram consideradas a extensão total de cais (input), a movimentação total das embarcações e a movimentação total de cargas (outputs). Os autores chegaram à conclusão de que a aplicação de DEA BCC orientada a output permite uma ordenação dos portos brasileiros e que a baixa eficiência operacional do porto do Rio de Janeiro deve-se ao fato de este estar superdimensionado para sua atual capacidade de movimentação de cargas.

É nesse contexto que se insere este trabalho, que procura realizar uma análise da eficiência de terminais de contêineres brasileiros, através da aplicação da Análise Envoltória de Dados às informações sobre movimentação, produtividade e infraestrutura instalada.

Em relação aos estudos aqui relatados, o presente artigo utiliza um conjunto de variáveis que foram utilizadas por vários dos estudos citados, tais como: a movimentação de 
carga (que foi utilizada em todos os estudos), a área do terminal (que foi utilizada por cinco dos sete estudos) e a extensão do cais (que foi utilizada por três estudos). A novidade trazida pelo presente trabalho está principalmente no tratamento da questão da produtividade, que só foi tratada pela pesquisa de Rios e Maçada (2006). Esse é um ponto importante, pois o foco apenas no volume de movimentação pode dar a falsa impressão de eficiência.

No que diz respeito aos modelos DEA utilizados, o presente estudo segue a linha dos trabalhos de Barros e Athnassiou (2004), Cullinane et al. (2005) e Wang e Cullinane (2006), que foram os únicos a analisar conjuntamente a eficiência global, a técnica pura e a de escala. Além disso, o presente artigo procura focar mais sua análise em uma amostra mais homogênea, evitando comparações entre unidades (portos ou terminais) que tenham operações diferentes.

Assim sendo, as principais contribuições do presente artigo para o estudo de eficiência nesta área se dão pela análise conjunta das eficiências, pelo foco em uma amostra mais homogênea (o que fortalece a comparação entre os terminais) e pela inclusão de uma análise com foco na produtividade (que gera uma visão mais pormenorizada da eficiência dos terminais sob análise).

\section{METODOLOGIA}

Esta pesquisa pode ser caracterizada, de acordo com o exposto por Vergara (2004), como sendo descritiva e quantitativa, pois procura-se, através da aplicação da análise envoltória de dados sobre as informações dos terminais de contêineres que fazem parte da amostra, expor características a respeito da performance dos mesmos.

O processo de amostragem é não probabilístico, pois parte-se de um universo naturalmente restrito, já que os terminais foram escolhidos a partir dos que faziam parte da Associação Brasileira de Terminais de Contêineres de Uso Público (ABRATEC). Isso traz algumas limitações de inferência, mas não invalida os resultados da pesquisa, visto que os terminais associados a ABRATEC são, assumidamente, os mais representativos no Brasil.

Esta pesquisa foi feita com base nos dados secundários colhidos do site da ABRATEC (www.abratec-terminais.org.br) referentes ao ano de 2007, e partiu dos dados sobre movimentação, produtividade e características técnicas de cada um dos 12 terminais associados. Porém, em virtude de problemas com a falta de algumas informações, a amostra final foi de 10 terminais (apresentados no quadro 01).

A seguir, tem-se uma descrição de cada variável coletada:

- Movimentação de Contêineres (MOV): representa a quantidade de contêineres, tanto de 20 pés quanto de 40 pés, movimentada durante o ano, incluindo embarque e desembarque.

- Produtividade na Movimentação de Contêineres (PRODUT): determina a quantidade de contêineres que é movimentada (embarcados e descarregados) por hora nos navios. Esse indicador está relacionado com a eficiência de cais e diretamente associado com a mão-de-obra e o número de equipamentos do cais dos terminais e/ou de bordo dos navios. 
- Área Total das Instalações (ÁREA): refere-se à área que o terminal possui para armazenagem dos contêineres. É medida em metros quadrados e está relacionada com a eficiência de pátio do terminal. Quanto maior a área das instalações maior a capacidade de armazenagem de contêineres no pátio.

- Extensão Média dos Berços (BERÇOS): os berços são os locais onde os navios atracam para as operações de carga e descarga dos contêineres. Quanto maior a quantidade de berços e maior o tamanho total dos mesmos, maior a capacidade do terminal, pois maior será o número de navios grandes que podem operar no terminal e maior o número de equipamentos de cais exigidos. Logo o tamanho médio é uma medida que consolida o tamanho total e o número de berços. Essa variável é medida em metros.

- Calado dos Berços de Atracação (CALADO): refere-se à profundidade dos berços de atracação e será medido em metros. Está relacionado com a capacidade de transporte dos navios operados nos terminais. Quanto maior a capacidade dos navios, mais profundo deve ser o calado.

A partir desses indicadores, preparou-se a análise multicriterial, considerando cada variável como um vetor de desempenho monocriterial. Como outputs considerou-se a MOV (output 01) e a PRODUT (output 02). Como inputs foram considerados a ÁREA (input 01), os BERÇOS (input 02) e o CALADO (input 03). Com essas variáveis, foram montadas duas modelagens de análise: a primeira, referente à produção (utilizando todos os inputs e apenas o output 01 ); a segunda, referente à produtividade (também utilizando todos os inputs e apenas o output 02). Tem-se, então, duas visões do desempenho dos terminais, uma em relação à produção (volume absoluto) e outra em relação à produtividade (volume relativo). Isso foi feito para que se pudesse incorporar na análise, de forma indireta, a mão-de-obra e os equipamentos disponíveis para movimentação. Assim, a produtividade nada mais é do que um indicativo da "eficiência" de movimentação, ou seja, rapidez na movimentação de contêineres em função da disponibilidade de pessoas e máquinas. $\mathrm{O}$ resumo dos dados utilizados pode ser observado no quadro 01 .

Para rodar o modelo, foi utilizado o software de DEA denominado SIAD (Sistema Integrado de Apoio à Decisão), apresentado por Meza et al. (2003). As modelagens aplicadas buscam a eficiência organizacional multidimensional na obtenção da maior MOV ou PRODUT possível com o menor uso possível de ÁREA, BERÇO e CALADO, considerando de maneira integrada todos os vetores de desempenho apresentados. Isso é feito através da utilização da Análise Envoltória de Dados (DEA), que mostra o quão um terminal é eficiente, no tratamento de seus inputs e outputs, em relação aos outros. Essa análise fornece um indicador que varia de 0 a 1 ou de $0 \%$ a $100 \%$, sendo que somente os terminais que obtêm índice de eficiência igual a um é que são efetivamente eficientes, ou seja, fazem parte da fronteira eficiente. Em termos práticos, o modelo procura identificar a eficiência de uma unidade comparando-a com os melhores desempenhos observados.

Segundo Macedo (2006), os modelos utilizados, desenvolvidos a partir do DEA, são capazes de conjugar em um único índice vários indicadores de natureza diferentes para a análise do desempenho organizacional. Pode-se perceber, então, que a modelagem possui as características de trabalhar diversas variáveis sem a necessidade de convertê-las para um 
padrão comum de unidade e de apoiar o processo decisório com uma técnica de natureza multicritério e, portanto, mais capaz de modelar a complexidade do mundo real.

\begin{tabular}{clccccc} 
DMU & Terminais & $\begin{array}{c}\text { MOV (qtde) } \\
\text { output 01 }\end{array}$ & $\begin{array}{c}\text { PRODUT (qtde/hr) } \\
\text { output 02 }\end{array}$ & $\begin{array}{c}\text { ÁREA (m2) } \\
\text { input 01 }\end{array}$ & $\begin{array}{c}\text { BERÇO (m) } \\
\text { input 02 }\end{array}$ & $\begin{array}{c}\text { CALADO } \\
\text { (m) input 03 }\end{array}$ \\
\hline 1 & Santos-Brasil & 833.486 & 65 & 484.000 & 253 & 12,80 \\
2 & Libra T-37 & 518.123 & 45 & 380.020 & 221 & 13,00 \\
\hline 4 & Tecon Rio Grande & 368.320 & 47 & 670.000 & 300 & 12,20 \\
5 & TCP & 338.000 & 30 & 220.000 & 328 & 12,50 \\
\hline 6 & TVV & 209.506 & 46 & 102.686 & 232 & 10,67 \\
\hline 7 & Sepetiba Tecon & 174.865 & 34 & 400.000 & 270 & 14,50 \\
\hline 9 & Tecon Salvador & 163.715 & 35 & 74.000 & 227 & 12,00 \\
10 & Tecon Suape & 160.000 & 30 & 280.000 & 330 & 15,50 \\
\hline 11 & Multi-Rio & 150.775 & 30 & 184.000 & 266 & 12,30 \\
\hline 12 & Libra T-1 Rio & 139.800 & 35 & 140.000 & 273 & 12,60 \\
\hline
\end{tabular}

Quadro 01 - Dados Utilizados na Análise

De acordo com Coelli et al. (1998), Charnes, Cooper e Rhodes (1978) propuseram um modelo que tinha uma orientação input e assumia retornos constantes de escala (CRS). Artigos subseqüentes têm considerado várias alternativas, dentre elas as de Banker, Charnes e Cooper (1984), em que o modelo de retorno variável de escala (VRS) foi proposto.

Assim, ainda segundo Coelli et al. (1998), um caminho intuitivo para introduzir DEA é por meio de razão. Para cada DMU, procura-se de obter uma medida de razão de todos os outputs sobre todos os inputs, ou seja, os pesos ótimos $\mathrm{u}_{\mathrm{j}} \mathrm{e} \mathrm{v}_{\mathrm{i}}$ são obtidos pela resolução do seguinte problema de programação matemática:

$$
\begin{aligned}
\operatorname{Max} E_{c}= & \frac{\sum_{j=1}^{s} u_{j} y_{j c}}{\sum_{i=1}^{m} v_{i} x_{i c}} \\
\text { S.a.: } \quad & \frac{\sum_{j=1}^{s} u_{j} y_{j k}}{\sum_{i=1}^{m} v_{i} x_{i k}} \leq 1, k=1,2, \ldots, c, \ldots, n \\
& u_{j} \geq 0, \forall j, \\
& v_{i} \geq 0, \forall i
\end{aligned}
$$

Nesse modelo, c é a unidade (DMU) que está sendo avaliada. O problema acima envolve a procura de valores para u e v, que são os pesos, de modo que maximize a soma ponderada dos outputs (output "virtual") dividida pela soma ponderada dos inputs (input "virtual") da DMU em estudo, sujeita à restrição de que esse quociente seja menor ou igual a um, para todas as DMUs. Em outras palavras, a função objetivo está sujeita à restrição de que, quando o mesmo conjunto de coeficientes de entrada e saída (os vários $\mathrm{v}_{\mathrm{i}} \mathrm{e} \mathrm{u}_{\mathrm{j}}$ ) for aplicado a todas as outras unidades de serviços que estão sendo comparadas, nenhuma unidade excederá $100 \%$ de eficiência ou uma razão de 1,00 .

De acordo com Macedo (2004), esse é um problema fracionário (não linear) de programação matemática de difícil solução, que pode ser mais facilmente resolvido transformando a relação em uma função linear, simplesmente considerando o denominador 
(soma ponderada dos insumos) da função objetivo igual a um. Os modelos DEA-CRS e DEAVRS podem então ser apresentados da seguinte maneira:

$$
\begin{aligned}
\text { Max } E_{c}= & \sum_{j=1}^{s} u_{j} y_{j c} \text { CRS } \\
\text { S.a.: } & \sum_{i=1}^{m} v_{i} x_{i c}=1 \\
& \sum_{j=1}^{s} u_{j} y_{j k}-\sum_{i=1}^{m} v_{i} x_{i k} \leq 0, k=1,2, \ldots, c, \ldots, n \\
& u_{j,}, v_{i} \geq 0, \forall i, j
\end{aligned}
$$

$$
\begin{array}{ll}
\text { Max } E_{c}= & \sum_{j=1}^{s} u_{j} y_{j c}+u^{\prime} \quad \text { VRS } \\
\text { S.a.: } \quad \sum_{i=1}^{m} v_{i} x_{i c}=1 \\
& \sum_{j=1}^{s} u_{j} y_{j k}-\sum_{i=1}^{m} v_{i} x_{i k}+u^{\prime} \leq 0, k=1,2, \ldots, c, \ldots, n \\
& u_{j}, v_{i} \geq 0, \forall i, j .
\end{array}
$$

Como foi possível observar nessas modelagens, a medida de eficiência DEA é mais completa que as medidas de desempenho monodimensionais, pois são capazes de incorporar uma análise multicriterial e assim modelar melhor a complexidade do mundo real. A eficiência técnica global é obtida com a fronteira CRS, que pode ser decomposta em eficiência técnica pura (obtida pela fronteira VRS) e eficiência de escala (CRS/VRS). Em suma, para uma empresa ser CRS eficiente ela precisa ter eficiência técnica (VRS) e de escala.

Esses modelos são utilizados para a análise dos dados, pois se tem três inputs e dois outputs utilizados de maneira alternada. Macedo (2006) diz que quanto maior a relação Soutputs / Einputs, maior a eficiência. Para cada DMU a ser analisada, formula-se um problema de otimização com o objetivo de determinar os valores que essa DMU atribuiria aos multiplicadores $\mathrm{u}$ e v, de modo a aparecer com a maior eficiência possível. Então, complementa o autor, o problema consiste em achar os valores das variáveis $\mathrm{u}_{\mathrm{j}} \mathrm{e} \mathrm{v}_{\mathrm{i}}$, que são os pesos (importância relativa de cada variável), de modo que se maximize a soma ponderada dos outputs (output "virtual") dividida pela soma ponderada dos inputs (inputs "virtual") da DMU em estudo, sujeita à restrição de que esse quociente seja menor ou igual a um, para todas as DMUs. Logo, as eficiências variam de 0 a 1 ou $0 \%$ e $100 \%$.

\subsection{Apresentação e Análise dos Dados}

Conforme dito anteriormente, para cada terminal foi calculado o desempenho com base nos modelos DEA-CRS e DEA-VRS. Esse procedimento pretende obter uma visão das eficiências técnicas global e pura e da eficiência de escala. Quando uma unidade é apenas VRS eficiente, isso quer dizer que toda a ineficiência está relacionada a problemas de escala. Cabe salientar que foram rodadas duas modelagens: foco na produção e foco na produtividade.

Para o modelo de produção, observou-se que a amostra tinha eficiências médias das seguintes magnitudes: $65,80 \%$ para a eficiência global, 90,63\% para a eficiência técnica e $70,61 \%$ para o caso da eficiência de escala. Daí já se pode ter uma idéia de que o problema para a amostra como um todo parece estar na eficiência de escala, já que a eficiência global é formada por uma combinação desta com a eficiência técnica, que apresenta um valor superior.

O quadro 02 mostra os valores das eficiências DEA-CRS (técnica global), DEA-VRS (técnica pura) e de escala dos terminais analisados. Como é possível observar, apenas os 
terminais Santos-Brasil, TVV e Tecon Salvador são 100 \% eficientes no modelo DEA-CRS. Isso quer dizer que apenas essas unidades é que possuem eficiência global (técnica e de escala). Esses serão os terminais utilizados como referência na análise de benchmarking, feita pela metodologia DEA com a finalidade de apontar melhorias nos índices de eficiência alcançados. Isso se dá pelo fato de serem esses terminais de destaque, em termos de desempenho multicriterial, em relação às variáveis estudadas no período analisado.

Em termos da eficiência técnica pura (DEA-VRS) tem-se, além dos terminais já citados, mais o terminal Libra T-37 eficiente. Como dito anteriormente, as unidades que são DEA-VRS eficientes, mas que não são DEA-CRS eficientes, têm seus problemas de desempenho relacionados a questões de escala de operação. Esse é o caso do referido terminal. Os outros terminais, que não são eficientes em nenhum dos modelos, apresentam problemas de eficiência técnica e de escala.

Com relação à eficiência de escala, percebeu-se que apenas os três terminais com eficiência global são eficientes. Essas unidades trabalham numa escala ótima de operação (retornos constantes).

Todos os outros terminais operam com retornos crescentes de escala. Nesses, um aumento dos outputs é superior proporcionalmente a um aumento dos inputs. Em outras palavras, acréscimos nos indicadores de infraestrutura geram aumentos mais do que proporcionais na movimentação de contêineres - economias de escala.

Além da análise do desempenho, o estudo procurou observar as melhorias necessárias nos valores dos inputs, mantendo-se o valor do output, das unidades de baixo desempenho no sentido de torná-las eficientes. Isso foi feito apenas para o modelo VRS, pois esse modelo compara as unidades apenas com outras de mesmo tamanho. Os valores ideais de input, no quadro 02, mostram esses alvos em termos de cada indicador de infraestrutura.

\begin{tabular}{lccccccc} 
DMU - Terminais & \multicolumn{3}{c}{ Indicadores } & \multicolumn{4}{c}{ Ideal VRS } \\
\cline { 2 - 8 } & CRS & VRS & Escala & Input 01 & Input 02 & Input 03 & Output 01 \\
Santos-Brasil & $100,00 \%$ & $100,00 \%$ & $100,00 \%$ & \multicolumn{4}{c}{ EFF GLOBAL } \\
\hline Libra T-37 & $78,65 \%$ & $100,00 \%$ & $78,65 \%$ & \multicolumn{3}{c}{ EFF TÉCNICA } & 658.731 \\
Tecon Rio Grande & $46,36 \%$ & $91,90 \%$ & $50,45 \%$ & 199.737 & 237 & 11,21 & 794.416 \\
\hline TCP & $83,19 \%$ & $88,87 \%$ & $93,61 \%$ & 181.209 & 236 & 11,11 & 406.303 \\
TVV & $100,00 \%$ & $100,00 \%$ & $100,00 \%$ & & EFF GLOBAL & \\
\hline Sepetiba Tecon & $24,96 \%$ & $83,43 \%$ & $29,92 \%$ & 272.582 & 225 & 12,10 & 700.567 \\
Tecon Salvador & $100,00 \%$ & $100,00 \%$ & $100,00 \%$ & & EFF GLOBAL & \\
\hline Tecon Suape & $31,04 \%$ & $70,04 \%$ & $44,32 \%$ & 124.798 & 231 & 10,86 & 515.432 \\
Multi-Rio & $43,40 \%$ & $87,13 \%$ & $49,81 \%$ & 108.335 & 232 & 10,72 & 347.397 \\
\hline Libra T-1 Rio & $50,35 \%$ & $84,93 \%$ & $59,29 \%$ & 106.370 & 232 & 10,70 & 277.638
\end{tabular}

Quadro 02 - Indicadores de Eficiência Técnica Global, Técnica Pura e de Escala e Valores Ideais de Inputs e Outputs para o Modelo Produção (output - MOV)

Percebe-se que as unidades CRS eficientes (como os terminais Santos-Brasil, TVV e Tecon Salvador), e ainda o terminal Libra T-37 (que é eficiente no modelo VRS) não precisam de melhoria alguma em seus inputs. Os terminais com alto desempenho, mas com eficiência diferente de 100 \% (como é o caso do Tecon Rio Grande) necessitam de pequenas mudanças em seu níveis de inputs para se tornarem VRS eficientes. Já as DMU's tidas como 
menos VRS eficientes (por exemplo, o terminal Tecon Suape) necessitam de mudanças mais radicais em seus níveis de inputs.

Além dessa análise para os níveis de input, considerando o modelo VRS, foi feita uma análise nos níveis de output, mantendo-se constantes os níveis de input, para que os terminais ganhassem escala e assim pudessem se tornar também CRS eficientes. Essa análise mostra o nível de movimentação necessária para tornar eficiente o terminal, dada sua infraestrutura disponível para operação (área, berço e calado). Nessa análise percebeu-se o mesmo do relatado anteriormente, ou seja, as maiores necessidades de mudanças se dão naqueles terminais com menor eficiência CRS. Vale salientar que o terminal Libra T-37 (que tem problemas de escala, pois é apenas VRS eficiente) precisa aumentar seu atual nível de movimentação. Os níveis ideais para a movimentação se encontram na última coluna do quadro 02.

Todo procedimento aplicado anteriormente, para o modelo de produção, foi repetido para o modelo de produtividade. Para esse modelo foi observado que a amostra tinha eficiências médias das seguintes magnitudes: $72,43 \%$ para a eficiência global, 89,93 \% para a eficiência técnica e 79,14 \% para o caso da eficiência de escala. Da mesma forma que no modelo de produção, existe um grande problema para a amostra como um todo na eficiência de escala.

O quadro 03 mostra, para o modelo de produtividade, os valores das eficiências DEACRS (técnica global), DEA-VRS (técnica pura) e de escala dos terminais analisados. Como pode-se observar, mais uma vez apenas os terminais Santos-Brasil, TVV e Tecon Salvador são $100 \%$ eficientes no modelo DEA-CRS, o que quer dizer que apenas essas unidades é que possuem eficiência global (técnica e de escala). Note, ainda, que esses terminais possuem eficiência global nos dois modelos. Isso, no entanto, não é necessariamente esperado, já que a lógica de eficiência nos dois modelos é diferente. No modelo de produção, o foco é a quantidade movimentada (sem levar em consideração a mão-de-obra e os equipamentos disponíveis). Já o modelo de produtividade procura incorporar esses elementos de capacidade, trabalhando como variável de saída um indicador relativo da movimentação por hora. Isso incorpora de forma indireta na análise a "eficiência" de movimentação do terminal, que não pode ser incorporada de forma direta pela consideração explícita das variáveis mão-de-obra e equipamentos, por conta dessas não estarem disponíveis na forma desejada.

Em termos da eficiência técnica pura (DEA-VRS) tem-se, além dos terminais já citados, o terminal Libra T-37 como eficiente, já que esse tem sua eficiência global afetada apenas pela ineficiência de escala. Os outros terminais, que não são eficientes em nenhum dos modelos, apresentam problemas de eficiência técnica e de escala. Além disso, apenas os três terminais com eficiência global trabalham numa escala ótima de operação (retornos constantes) e todos os outros terminais operam com retornos crescentes de escala, do mesmo modo que foi observado na análise anterior.

$\mathrm{Na}$ análise das melhorias necessárias nos valores dos inputs, mantendo-se o valor do output, das unidades de baixo desempenho no sentido de torná-las eficientes, chegou-se a resultados parecidos com aqueles encontrados no modelo de produção. O mesmo se aplica a melhorias na produtividade. Os valores ideais para todos os indicadores podem ser vistos nas últimas colunas do quadro 03 . 


\begin{tabular}{lccccccc} 
DMU - Terminais & \multicolumn{3}{c}{ Indicadores } & \multicolumn{3}{c}{ Ideal VRS } \\
\cline { 2 - 8 } Santos-Brasil & CRS & VRS & Escala & Input 01 & Input 02 & Input 03 & Output 02 \\
\hline Libra T-37 & $100,00 \%$ & $100,00 \%$ & $100,00 \%$ & \multicolumn{5}{c}{ EFF GLOBAL } \\
Tecon Rio Grande & $81,71 \%$ & $100,00 \%$ & $81,71 \%$ & EFF TÉCNICA & 55 \\
\hline TCP & $75,86 \%$ & $88,38 \%$ & $85,84 \%$ & 122.755 & 233 & 10,78 & 62 \\
\hline TVV & $53,00 \%$ & $85,36 \%$ & $62,09 \%$ & 102.686 & 232 & 10,67 & 57 \\
\hline Sepetiba Tecon & $52,53 \%$ & $83,43 \%$ & $62,97 \%$ & 272.582 & 225 & 12,10 & 65 \\
Tecon Salvador & $100,00 \%$ & $100,00 \%$ & $100,00 \%$ & & EFF GLOBAL & \\
\hline Tecon Suape & $42,62 \%$ & $70,04 \%$ & $60,86 \%$ & 124.798 & 231 & 10,86 & 70 \\
Multi-Rio & $54,73 \%$ & $87,13 \%$ & $62,81 \%$ & 108.335 & 232 & 10,72 & 55 \\
\hline Libra T-1 Rio & $63,83 \%$ & $84,93 \%$ & $75,16 \%$ & 106.370 & 232 & 10,70 & 55
\end{tabular}

Quadro 03 - Indicadores de Eficiência Técnica Global, Técnica Pura e de Escala e Valores Ideais de Inputs e Outputs para o Modelo Produtividade (output - PRODUT)

Em cada um dos modelos mostrou-se não só a eficiência, mas as mudanças necessárias nos indicadores utilizados para se atingir a eficiência. Em termos gerenciais, não faz sentido a indicação de redução nos inputs, pois não há como reduzir (pelo menos no curto prazo) a área disponível, e é impensável uma redução no tamanho médio e na profundidade dos berços. O que se tem como indicação, nesse caso, é em primeira instância um aumento da movimentação, que pode ser alcançada pelo aumento da produtividade. O que pode estar acontecendo com os terminais que não conseguem manter uma relação eficiente entre infraestrutura disponível e movimentação é que a utilização dos insumos disponíveis (mão-deobra e equipamentos) é mal feita. Isso pode estar demonstrando problemas de processos e procedimentos na movimentação dos contêineres, além de questões tecnológicas dos equipamentos utilizados e de treinamento da mão-de-obra.

Esses indicadores de eficiência, obtidos pela aplicação da DEA, só podem mesmo fazer sentido se utilizados com outros fatores, que em conjunto podem oferecer uma explicação sobre o mau desempenho de cada terminal e mostrar os caminhos alternativos para melhoria nos indicadores de eficiência.

Uma análise das variáveis, tendo como base o modelo DEA-VRS, para verificar aquelas que se apresentam problemáticas para os terminais, revelou que a área total das instalações é a variável com maior discrepância entre os terminais da amostra analisada. Primeiramente, essa é a variável que apresenta a maior necessidade de melhoria, uma redução de mais de $40 \%$ em ambos os modelos (produção e produtividade). Além disso, essa variável foi aquela que apresentou maior relação entre desvio padrão e média, ou seja, é aquela com mais dispersão em termos relativos. E, por fim, é a variável que apresentou o maior número de pesos zero na resposta da modelagem DEA-VRS.

Essa abordagem dos pesos zero, vale notar, é feita para saber quais variáveis estão sendo "desprezadas" na análise de desempenho. Em linhas gerais, quando uma variável tem peso (u ou v) igual a zero, isso representa que essas variáveis são naturalmente problemáticas na obtenção dos índices de eficiência, ou seja, existe uma grande diferença na relação entre utilização desse input e o output pelas várias DMU's analisadas. Como a modelagem procura os melhores índices de desempenho, dadas as características de inputs e outputs, para cada DMU, atribui zero a toda variável que possa atrapalhar o objetivo de maximizar a eficiência. 


\section{CONSIDERAÇÕES FINAIS}

A avaliação de desempenho é um dos aspectos que vêm governando, em maior ou menor grau, dependendo da organização, a atuação de terminais de contêineres no Brasil e no mundo, por conta da necessidade de agilidade na movimentação de cargas, principalmente envolvendo operações de importação e exportação.

Apesar de não existir um modelo de avaliação de desempenho organizacional que seja único para todas as variáveis do mundo empresarial, alguns métodos são capazes de considerar aspectos diversificados, assumindo, assim, um papel crucial na avaliação da performance empresarial - como a medida de eficiência DEA, utilizada neste trabalho.

De modo geral, pode-se perceber que a resposta mais importante dessa metodologia é a caracterização de uma medida de eficiência, que faz com que a decisão fique orientada por um único indicador construído a partir de várias abordagens de desempenho diferentes. Vale ressaltar, que isso facilita o processo decisório, pois, ao invés de considerar vários índices para concluir a respeito do desempenho da empresa ou da unidade sob análise, o gestor pode se utilizar apenas da medida de eficiência da DEA. Além disso, existem outras informações oriundas dessa metodologia que podem ser utilizadas para auxiliar a empresa na busca pela excelência.

Numa análise dos resultados apresentados, pode-se perceber que os melhores terminais são aqueles que possuem um desempenho multicriterial superior. Nota-se que vários terminais precisam melhorar bastante, e que esses são exatamente aqueles que obtiveram os menores índices de eficiência. Isso quer dizer que unidades como os terminais Santos-Brasil, TVV e Tecon Salvador estão com desempenho relativo superior e podem ser utilizadas como benchmarks para os demais.

Percebe-se, em termos de eficiência, que apenas três unidades são $100 \%$ eficientes no modelo DEA-CRS, e que na eficiência técnica pura (DEA-VRS) tem-se mais um terminal. Já com relação à eficiência de escala, apenas os terminais com eficiência global é que alcançaram $100 \%$, e os outros terminais operam com retornos crescentes de escala. Além disso, observa-se que o maior problema para a amostra, como um todo, parece estar na eficiência de escala, já que essa se mostra, em média, menor que a eficiência técnica. Isso está em consonância com o que foi encontrado em outros estudos, tais como Barros e Athnassiou (2004), Cullinane et al. (2005), Wang e Cullinane (2006) e Fontes e Mello (2006).

Em relação à análise gerencial dos indicadores de eficiência obtidos, pode-se dizer que os terminais devem buscar um aumento da movimentação e, por conseguinte, das produtividades, tendo como base as indicações advindas da análise de benchmarking. Percebe-se que, de maneira geral, os terminais ineficientes não conseguem manter uma relação ótima entre infraestrutura disponível e movimentação. Isso pode estar demonstrando problemas de processos e procedimentos na movimentação dos contêineres, além de questões tecnológicas dos equipamentos utilizados e de treinamento da mão-de-obra.

Os resultados deste estudo propõem uma nova percepção sobre a performance de terminais de contêineres que não se encontra disponível aos gestores através dos métodos tradicionais de análise. Ou seja, a partir de informações que não estariam disponíveis pelas técnicas convencionais, os resultados da análise envoltória de dados podem proporcionar melhores condições de competitividade aos terminais, principalmente quando interpretadas e 
usadas com os conhecimentos e julgamentos próprios sobre suas operações. Isso só é possível porque a metodologia DEA é capaz de munir a administração dos terminais de informações adicionais sobre os maiores determinantes de eficiência ou ineficiência, partindo-se de variáveis pré-selecionadas, pois oferece uma análise de benchmarking com a qual o gestor pode avaliar as alterações necessárias para que a organização possa se tornar eficiente em termos competitivos.

O assunto não se encontra encerrado, pois ainda há muito a ser explorado desta metodologia na gestão de terminais portuários. Este mesmo trabalho, portanto, deve ter continuidade através de uma melhor visão dos vetores de desempenho que mais contribuem para uma mensuração mais apurada da eficiência organizacional, aplicando a metodologia aqui apresentada e discutida combinada com outras metodologias, tais como as análises discriminante e fatorial e a regressão logística.

\section{REFERÊNCIAS}

ABRATEC - Associação Brasileira de Terminais de Contêineres de Uso Público. Disponível em <HTTP://www.abratec-terminais.org.br>. Acesso em 10 jan. 2008.

BANDEIRA, D.L. Alocação e movimentação de contêineres vazios e cheios - um modelo integrado e sua aplicação. Tese (Doutorado em Administração). Porto Alegre: Universidade Federal do Rio Grande do Sul, 2005.

BANKER, R. D.; CHARNES, A.; COOPER, W. W. Some Models for Estimating Technical and Scale Inefficiencies in Data Envelopment Analysis. Management Science. v. 30, n. 9, 1078-1092. 1984.

BARROS, C.P.; ATHANASSIOU, M. Efficiency in European Seaports with DEA: Evidence from Greece and Portugal. Maritime Economics \& Logistics. v. 6, n. 2, p. 122-140, 2004.

CAMP, R. C. Benchmarking: the search for industry best practices that lead to superior performance. New York: Quality Resources, 1989.

CHARNES, A.; COOPER, W. W.; RHODES, E. Measuring the Efficiency of Decision Making Units. European Journal Of Operational Research. v. 2, n. 6, 429-444. 1978.

CHARNES, A.; COOPER, W. W.; LEWIN, A. Y.; SEIFORD, L. M. Data Envelopment Analysis. 2. ed. Boston: KAP, 1994.

COELli, T.; RAO, D. S. P.; BALTESE, G. E. An Introduction to Efficiency and Productivity Analysis. Boston: KAP, 1998.

CULliNANE, K; SONG, D.; JI, P.; WANG, T. An Application of DEA Windows Analysis to Container Port Prodution Efficiency. Review of Network Economics. v. 3, . 2, p. 186208, 2004

CULLINANE, K.; SONG, D.; WANG, T. The Application of Mathematical Programming Approaches to Estimating Container Port Production Efficiency. Jornal of Productivity Analysis. v. 24, n. 1, p. 73-92, 2005. 
FONTES, O. H. P. M.; MELLO, J. C. C. B. S. Avaliação da eficiência portuária através de uma modelagem DEA. In: SIMPOSIO DE PESQUISA OPERACIONAL DA MARINHA, 9, 2006, Rio de Janeiro. Anais do IX SPOLM. Rio de Janeiro: SPOLM, 2006.

HIJJAR, M .F.; ALEXIM, F. M. B. Avaliação do acesso aos terminais portuários e ferroviários de contêineres no Brasil. 2006. Disponível em $<$ http://www.cel.coppead.ufrj.br>. Acesso em 10 out. 2007.

LINS, M. P. E.; MEZA, L. A. Análise Envoltória de Dados: Perspectivas de Integração no Ambiente do Apoio à Decisão. Rio de Janeiro: COPPE/UFRJ, 2000.

MACEDO, M. A. S. Indicadores de Desempenho: Uma Contribuição para o Monitoramento Estratégico através do Uso de Análise Envoltória de Dados (DEA). In: SIMPÓSIO DE ADMINISTRAÇÃO DA PRODUÇÃO, LOGÍSTICA E OPERAÇÕES INTERNACIONAIS, 7, 2004, São Paulo. Anais do VII SIMPOI. São Paulo: FGVSP, 2004b. 1 CD.

MACEDO, M. A. S. Seleção de PSL's com Base no Desempenho Organizacional. Revista Alcance. v. 13, n. 2, p. 267-286, 2006.

MEZA, L. A.; BIONDI NETO, L; SOARES DE MELlO, J. C. C. B.; GOMES. E. G.; COELHO, P. H. G. SIAD - Sistema Integrado de Apoio à Decisão: uma implementação computacional de modelos de análise de envoltória de dados. In: SIMPÓSIO DE PESQUISA OPERACIONAL DA MARINHA, 6, 2003, Rio de Janeiro. Anais do VI SPOLM. Rio de Janeiro: CASNAV, 2003. 1 CD.

NEELY, A. Measuring Business Performance. London: The Economist Books, 1998.

NOVAES, A. G. Logística e Gerenciamento da Cadeia de Distribuição. Rio de Janeiro: Campus, 2001.

RIOS, L. R.; MAÇADA, A. C. G. Seleção de variáveis para medir a capacidade de um terminal de contêineres. In: SIMPÓSIO BRASILEIRO DE PESQUISA OPERACIONAL, 34, 2002, Rio de Janeiro. Anais do XXXIV SBPO. Rio de Janeiro: SOBRAPO, 2002. 1 CD.

RIOS, L. R. Medindo a eficiência relativa das operações dos terminais de contêineres do Mercosul. Dissertação (Mestrado em Administração). Porto Alegre: Universidade Federal do Rio Grande do Sul, 2005.

RIOS, L.R.; MAÇADA, A.C.G. Medindo a Eficiência Relativa das Operações dos Terminais de Contêineres do Mercosul Utilizando a Técnica de DEA e Regressão Tobit. In: ENCONTRO DA ASSOCIAÇÃO NACIONAL DE PÓS-GRADUAÇÃO E PESQUISA EM ADMINISTRAÇÃO, 30, 2006, Salvador. Anais do XXX EnANPAD. Salvador: EnANPAD, 2006.

ROLL, Y.; HAYUTH, Y. Port Performance Comparison Applying DEA. Maritime Policy and Management. v. 20, n. 2, p. 153-161, 1993.

SLACK, N.; CHAMBERS, S.; HARLAND, C.; HARRISON, A.; JOHNSTON, R. Administração da Produção. 2 ed. São Paulo: Atlas, 2002. 
VERGARA, S. C. Projetos e Relatórios de Pesquisa em Administração. 5 ed. São Paulo: Atlas, 2004.

WANG, T.; CULlinANE, K. The Efficiency of European Container Terminals and Implications for Supply Chain Management. Maritime Economics \& Logistics. v. 8, n. 1, p. 82-99, 2006. 